УДК 821.162.1-31.09 Токарчук

\author{
Мохначева Ольга, \\ кандидат филологических наук, \\ доцент кафедры русской филологии \\ и зарубежной литературы \\ Криворожский государственный \\ педагогический университет
}

\title{
КЛЮЧЕВЫЕ ПРИЕМЫ СОЗДАНИЯ ХУДОЖЕСТВЕННОЙ РЕАЛЬНОСТИ В ЭКОЛОГИЧЕСКОМ РОМАНЕ НОВОГО ТИПА «ВЕДИ СВОЙ ПЛУГ НАД КОСТЯМИ МЕРТВЫХ» ОЛЬГИ ТОКАРЧУК
}

\begin{abstract}
У статті досліджуютъся прийоми, за допомогою яких реалізовано авторсъку стратегію Олъги Токарчук у романі «Веди свій плуг понад кістками мертвих», який можна визначити як «екологічний роман нового типу», оскільки в нъому, поряд з екологічними, ставлятъся й вирішуютъся проблеми морального характеру. Помічено, шо для творчої тактики Токарчук характерні різомна жсанрова стратегія, суб'єктна авторсъка модальність, акцент на паратекстуальних складових тексту та інші прийоми. В романі Токарчук відтворено художню реальність з проекціею в метафізичні смисли, що дозволяе говорити про тему екологї морального почуття.
\end{abstract}

Ключові слова: екологічний роман, прийом, авторсъка модальністъ, різомна жсанрова стратегія, елементи nаратексту.

Mohnachova O. Key techniques of creating art reality in the ecological novel of a new type "Lead your plouch over the bones of the dead» by Olga Tokarchuc.

In the article techniques are investigated with the help of which Olga Tokarchuk's author's strategy is realized in the novel "Lead your plough over the bones of the dead" which can be determined as "an ecological novel of a new type" since besides ecological problems of moral character are raised and solved in it. It is stressed that Olga Tokarchuc's characteristics of creative individuality is the masterful using of text characters that are attractive to the readership, such as a special heroine, corresponding to the type of trickster demanded in modern literature; a series of mysterious deaths; opposition to the forces of evil, etc. Such authorial strategies contribute to building the text as a multi-genre structure, for which both the external series of events and the hidden semantic plan are equally important.

It is noticed that the artistic reality in the novel Tokarchuk was created using a variety of techniques: switching attention from particular to general and vice versa; paradox; constant change of angle and scale. Core techniques for 
138Літератури світу: поетика, ментальність і духовністъ. 2020. Bип.14

Tokarchuc's creative tactics are typical rhizome genre strategy, subjective author's modality, an accent on paratextual components of the text are revealed.

Because of such a strategy, Tokarchuk realized an ecological novel in a new form, the classic example of which is "Roots of Heaven" by Romain Gary, outlined to contemporaries global goals: to protect the ideals and values of humanism, saving nature. For Olga Tokarchuk's novel, it's important that the problem of nature protection develops into an ecology of morality, exposing the question of the permissibility of murder, practically crime and mob law, as a way to fight for the rights of animals or defenseless people, similar to the heroine of the novel against those whom the writer calls "hunters." Art reality is depicted in Tokarchuк's novel with projection in metaphysical senses and, therefore, it allows to talk about the theme of ecological of a moral feeling.

Key words: an ecological novel, a technique, author's modality, rhizome genre strategy, elements of paratext.

Постановка проблемы. Интерес к творчеству польской писательницы Ольги Токарчук, неизменно сопровождающий каждую из ее литературных заявок, безусловно усилит и поддержит Нобелевская премия, присужденная ей в 2018 году и врученная, наконец, в 2019-м, «за нарративное воображение, которое с энииклопедической страстью представляет пересечение гранич, как форму жизни» (Сайт Нобелевского комитета). Эта победа в борьбе за международный высший литературный приз тем значительнее, что соперниками Токарчук были именитые писатели, например, близкая ей по взглядам канадская феминистка Маргарет Этвуд, француженка из Гваделупы Мариз Конде, Людмила Улицкая и Харуки Мураками.

Несмотря на то, что Ольга Токарчук широко известна европейскому сообществу и ее творчество оценено как многочисленными наградами, так и запросами читательской аудитории и вниманием критики, нарастающий по экспоненте художественный материал, разнообразно реализующийся в ее рассказах, романах и в поэзии представляет все более и более богатый материал для исследования.

Анализ последних публикаций. Корпус критических работ, посвященных личности и творчеству Ольги Токарчук, растет по уровню научного подхода и по поставленным задачам в диапазоне от рецензий и журнальных обзоров до диссертационных исследований и монографий. Позицию Токарчук принято рассматривать в контексте поколения писателей «новой польской прозы», или «младшего поколения» 90-x, у представителей которого есть ряд характерных черт, например - обращение $\kappa$ традициям Гофмана и хронотопу утопии и антиутопии» [1]. В ряде статей и в докторской диссертации (2005) романы Ольги Токарчук исследованы И. Е. Адельгейм с позиций анализа текстового пространства польской прозы с целью «выявления 
смыслов и их контекстов, которые молодая проза ввела в общее сознание как формы и понятия нового языка» [2].

В постмодернистской парадигме прозу писательницы анализировали Н. Н. Старикова, считая ее «визитной карточкой постмодернизма» [3], и М.Е.Шульгун, которая определяет жанровые эксперименты Токарчук «травелог $i$ роман-подорож як пошуки $i$ зонди сучасноӥ літератури» [4, с.84]; с позиций гендера к таким исследованиям подходила Л.Брега [5]; многие исследователи отмечают в поэтике Токарчук функции времени, разные аспекты мифологизма («імітацію мібопоетичного хронотопу» находит Н. М. Ткачик [6]); особенности реализации отдельных концептов заметили О. Сливинський («nутешествие» [7]) и К. Родик («квест-мандри» [8]) и др. Часто анализируются отдельные произведения писательницы, относится это и к роману «Веди свой плуг над костями мертвых» (О. Галета [9]). Тем не менее, многогранное творчество Ольги Токарчук дает возможность находить новые аспекты в ее мировоззрении и писательской стратегии, что наряду с повышенным интересом к писательнице определяет актуальность данного исследования.

Целью работы является определение и анализ приемов, которые играют ключевую роль в воссоздании самобытной художественной реальности романа Ольги Токарчук «Веди свой плуг над костями мертвых» и позволяют расценивать его как экологический роман нового типа.

Изложение основного материала. Начиная с литературного дебюта в 1989 году, Токарчук заявила о себе как о «своей среди чужих» (Р. Ханукаева) - незаурядном писателе, психологе-практике и эко-активистке, вызывая общественные дискуссии своей позицией по самым наболевшим для современности проблемам, которые и стали материалом для художественного переосмысления в ее творчестве. Развиваясь в русле «новой польской прозы», писательница, тем не менее, обладает уникальным звучанием, что в равной степени касается и тематической нагрузки ее произведений, и их особого языка.

В критике замечено, что важную роль в творчестве Токарчук играет тема «малой родины», понятой как фокус и микроточка концентрации проблематики космического масштаба. Вторая доминантная тема отмеченное Нобелевским Комитетом «пересечение границ», «межсова, гранична територія - важливий топос текстів Токарчук, що маркуе стан переходу $i$ змін» [10]. Обе эти темы, как и многие другие, отличающие художественную индивидуальность Токарчук, сосредоточены в романе «Веди свой плуг над костями мертвых», но 
при первом впечатлении позволяют увидеть только внешнюю интригу детективную составляющую, что иногда дает основания рассматривать роман как «глубоко антихристианский» и «пропагандирующий экологический терроризм» [1].

Авторские стратегии текста работают таким образом, что под набором привлекательных для читательской аудитории знаков текста - чудаковатая героиня, не вполне социализированная, но наделенная интеллектом, незаурядная и самокритичная (тип трикстера, востребованный в современной литературе); череда таинственных смертей; противостояние с силами зла; ряд странных персонажей из близкого круга Янины Душейко («Cтарые эксцентрики. Хипnи божъей милостъю») и пр. - постепенно проявляются очертания «глубокого романа с двойным дном под маркетинговым решением для массовой литературы» [11].

Роман расценивают как ретро-детектив (Юлиуш Куркевич), экологический детектив или философский триллер, эко-триллер, антропологический роман, в нем видят признаки антиутопии, сама Токарчук определила жанр романа как «сказку с элементами политического памфлета». Основания для таких определений дает полижанровая природа романа, что позволяет увидеть самый очевидный прием, использованный Токарчук: ризомная жанровая стратегия, с помощью которой она выстраивает сложную конструкцию текста, сосредоточенного не столько на событиях, сколько на исследовании человеческой природы во всех смыслах слова и Слова как способа такого исследования. Героиня романа - не только сторож поселка из семи пустых домов на Плоскогорье, она хранительница Вселенной, сосредоточенной в малой точке отдельного бытия, сама Человек-Вселенная, уверенная в уникальности и бесценности любого Существа. Ключ к этой Вселенной - Слово, используемое в тексте и как название, и как обозначение, и как имя, и как молитва, потому что «любой nоступок адресован Космосу», а слово фиксирует и порождает смыслы.

Фирменные знаки художественной вселенной Токарчук многообразны: это и прием переключения внимания от частного к общему и обратно, например, от истребления ЖКивотных к несовершенству человеческого проекта («кто-то нас плохо спроектировал» $[12$, с. 34]), и парадокс («иногда мне кажется, что только больной может бъть действительно здоровым» [12, с. 35], и постоянная смена угла зрения и масштаба - от Космоса до подвала с летучими мышами. Значимы в этом плане и выбор формы 
повествования - от первого лица и, в особенности, выбор личности рассказчицы, положительной героини, но по факту - убийцы (что остается скрытым в ее исповеди до самого финала романа). Пани Душейко убедительно обосновывает свой крестовый поход, правда по большому счету на ее стороне, т.к. она выступает от лица «малых сих»; трагическое противоречие между причиной и следствием ее деяний в определенной мере снимает авторская ирония.

В реализации авторского намерения текста и понимании глубины поставленных в романе проблем ключевую смыслообразующую роль играет такой прием как авторская модальность. Способ выражения авторской модальности в тексте может реализовываться в повествовательной форме и выбранном субъекте повествования, конструируется речевыми средствами и носит субъективный или объективный характер. В романе «Веди свой плуг над костями мертвых» повествование идет от первого лица, что подчеркивает значение субъектности авторской модальности. Субъектная авторская модальность проявляется в романе через выстраивание отрезков текста, его эмоциональное окрашивание, через оценочно-авторское отношение как к самой теме, так и к особенностям ее решения, а также через характеристику персонажей. Так, плохие люди - охотники, комендант-апоплектик, «тип Человека, который презирает то, чего не понимает» $[12$, с. 22], убежденный браконьер «жестокий Мужчина» Большая Ступня, живодер Нутряк и другие недруги животного мира из их племени определенно не вызывают читательских симпатий, что обусловлено авторской подачей.

Активно влияет на восприятие задания текста прием, формирующий смысловую глубину романа, - акцент на его паратекстуальных составляющих, в особенности, на эпиграфе и заглавии. Согласно широко распространенной в постмодернистской практике концепции Жерара Женетта о паратексте как типе межтекстовых отношений, текст представляет собой систему, взаимообусловленную и взаимосвязанную с элементами, его составляющими - эпиграфом, заглавием, предисловием, послесловием и т.д. Заглавие - важнейшая единица текста, служит ключевой фразой или словом, инициирующим его смысловые уровни. В романе Токарчук «Веди свой плуг над костями мертвых» заглавие - это строчка из поэта-мистика XVIII века Уильяма Блейка, на ключевую роль которого указала сама писательница: «Эта книга очень насыщена Уильямом Блейком, его поэзией. Но не только поэзией, но и философией. Блейк был прежде бунтарем, поэтом антиистеблишментским. И я хотела этот дух Блейка вставить в 
142 Літератури світу: поетика, ментальність $i$ духовність. 2020. Bип. 14

свою книгу. Там есть иитаты из него, есть персонажи, которые переводят Блейка. А прежде, во времена Блейка, в старой английской поэзии существовала такая манера - писать некоторые выражсения с большой буквы, чтобы подчеркнуть их значение. И я использовала этот прием, как такой формальный эксперимент. Но одновременно, посколъку повествование ведется от первого лица, то это также демонстрирует способ рассказчицы» [13].

Роман выстроен из 17 глав, у каждой из которых «говорящее» название-метафора, связанное с заглавием и с текстом эпиграфами, в большинстве случаев из Блейка; эти элементы играют роль определенного стержня, вокруг которого собраны текстовые смыслы и авторские задания. Например, название первой главы «A теперь внимание!» настраивает на то, что разговор в романе пойдет о праведности и конечности человеческого бытия и подкрепляется эпиграфом из «Бракосочетания Неба и Ада» Уильяма Блейка:

Некогда, кроток душой,
По опасной тропе
Праведный шел человек,
Пробираясь долиною смерти $[12$, с. 3$]$.

Такой интертекстуальный прием, как отсылки к авторитету Блейка, всплывает в самые неожиданные моменты на протяжении всего романа, они носят отчасти шутливый, отчасти побудительный характер, подкрепляя размышления героини, например: «mom, кто чувствует Гнев, но не действует, распространяет заразу. Так говорит наш Блейк» [12, с. 26]. В некоторых случаях отсылки к Блейку усиливают пафос текста, служат опорой в мире хаоса и беззакония, потому что сказанное однажды и сохранившееся в коллективной памяти имеет особую нравственную силу: «Здесъ, внизу, в мире Уризена, (мифологический создатель, персонаж книги Уильяма Блейка «Книга Уризена») действует закон. От звездного неба к морали и совести. Это строгий закон, безжалостный, он не признает исключений» [12, с.27]. Героиня опирается на опыт поэта, когда обосновывает «экономичную формулу» своей житейской философии: «все, о чем мъ можем подумать - это некий вид действительности, - процитировала я Блейка» [12, с. 100]. Токарчук здесь транслирует идею о созидательной силе и материальности мыслеформы, что и выводит романную действительность в сферу экологии мыслительной деятельности. 
Особенности экологического романа, реализованного Токарчук в новой форме, явственно видны при сравнении с первым и классическим жанровым образцом - романом Ромена Гари «Корни неба» (1956), где автор поставил перед собой глобальную цель: защитить гуманизм «всеми силами от разгула тоталитаризма, начионалистов, расистов, мистиков и манъяков» [14, с. 1]. Общее в них - идеалист-одиночка, тревожащий совесть человечества, и косное сопротивление жестокого хаоса мира. Различия - в том, что борьба против массового истребления слонов в Чаде при всей экзотичности в «Корнях неба» вписана в прозаическую реальность, подтверждается фактами и свидетельствами конкретных событий и персонажей; в романе Токарчук против охотников действуют условные Животные-мстители, хотя на самом деле акты возмездия совершает слабая женщина, старая чудачка с повышенной мерой ответственности за все живое. Мотив охоты на плохих людей у Гари имеет прямое воплощение (акции Мореля), у Токарчук же - это местная немецкая легенда о Ночном Охотнике, то есть перенос в обобщение и зону архетипа. Символ слонов во французском романе приобретает значение уходящих идеалов эпохи гуманизма; Токарчук намечает очертания нового справедливого порядка, основанного на экологии внутреннего мира, за который ответственен персонально каждый: «Нам кажется, что мы свободны, а Бог нам простит. Лично я так не считаю. Любой поступок, превратившись в едва ощутимое колебание фотонов, направится в конце концов к Космосу, как будто фильм, который вечно будут смотретъ планеты» [12, с. 20]. Токарчук создает очертания нового мира с тонкими ценностными гранями, - не границами! - на внутреннем молекулярном уровне, на уровне экологии нравственного чувства, не теряя при этом иронического самоконтроля (Чего стоит, например, мифическая Чехия, которая в пространстве романной действительности граничит с Плоскогорьем, но в версии пани «Душечки» существует как безусловная утопия, как уровень сравнения и этический образец).

Выводы и перспективы исследования. Как видим, новаторство и виртуозное мастерство писательницы в использовании разнообразных ключевых приемов в романе «Веди свой плуг над костями метрвых» - ризомная жанровая стратегия; прием переключения внимания от частного к общему и обратно; привлекательные для читательской аудитории знаки текста; такие интертекстуальные приемы, как «говорящее» название-метафора и эпиграфы-смысловые ориентиры, а также субъектная авторская модальность - обогащают 
художественную реальность романного пространства, наполняют его глубокими смысловыми зонами, активизируют читательский интерес и, что важнее всего, концентрируют внимание на нравственном конфликте: допустимо ли убийство «по совести» как средство борьбы за экологию природы, если при этом страдает экология нравственная. Такой акцент и позволяет определить произведение Токарчук как экологический роман нового типа.

В качестве перспективы для дальнейшего исследования творчества Ольги Токарчук, в частности, романа «Веди свой плуг над костями мертвых», можно отметить такие замеченные в тексте неизученные аспекты, как мотив инициации; особенности исповедальности как способа реализации авторского голоса, и в особенности, тему построения нового мира с новыми правилам, заявленную писательницей ранее в сборнике «Игра на разных барабанах» (2001): «подобия сплетают вещи в хитроумную сеть, которая удерживает сложную прическу мира в безмятежном порядке» [15].

\section{Литература}

1. Ханукаева Р. Ольга Токарчук: своя среди чужих. Издательская группа ЭКСМО. 08 ноября 2019. URL: https://eksmo.ru/trends/olgatokarchuk-svoya-sredi-chuzhikh-ID15525036/ (дата обращения: 05.01.2020)

2. Адельгейм И.Е. Поэтика молодой польской прозы 90-х годов ХХ века: автореф. дис. на соискание науч. степени д-ра филол. н.: 10.01.03 / Москва, 2005. 40 c. URL: http://cheloveknauka.com/poetikamolodoy-polskoy-prozy-90-h-godov-xx-veka\#ixzz6ABemJDTr (дата обращения: 04.01.2020)

3. Старикова Н. Н. Национальная идентичность славянских литератур в эпоху глобализации. Парадокс постмодернизма. Славянский альманах. 2014. №1/2. C. 22-23. URL: https://cyberleninka.ru/ article/n/natsionalnaya-identichnost-slavyanskih-literatur-v-epohuglobalizatsii-paradoks-postmodernizma (дата обращения: 28.12.2019).

4. Шульгун М. Ідентичність постмодерної людини: «Фланер» у сучасному травелозі та романі-подорожі (Патрік Модіано «Одного разу вночі», Ольга Токарчук «Бігуни»). Слово і час. 2016. № 12. C. 83-89.

5. Брега Л. О. Гендерна природа психологізму у творах О. Забужко та О. Токарчук: автореф. дис. на здобуття наук. ступ. к. філол. н.: 10.01.05. Бердянськ, 2016. 20 с. 
6. Ткачик Н. М. Міфопоетичний хронотоп як змістова категорія творів про історію роду. Прикарпат. вісн. НТШ. Сер.Слово. 2012. № 2. C. 223-229. - URL: www.irbis-nbuv.gov.ua $>$ irbis_nbuv $>$ cgiirbis_64 (дата звернення: 10.01.2020).

7. Сливинський О. Між паломництвом і втечею: подорож у романах Ольги Токарчук. Літакцент. 2010. Вип. 2 (4). С. 557-560.

8. Родик К. Детектив під знаком Нептуна. Україна молода. 2011. № 70. С.11. - Рецензия на роман О. Токарчук «Веди свій плуг понад кістками мертвих». Львів, 2011. 234 с.

9. Галета О. Антропос, топос, тропос, чи Народження антропологічного роману? ЛітАкцент. URL: http://litakcent.com/2011/10/20/ antropos-topos-tropos-chy-narodzhennja-antropolohichnoho-romanu/ (дата звернення: 9.01.2019).

10. Романцова Б. За що Ольга Токарчук отримала Нобелівську премію. 11.10.2019. URL: http://litakcent.com/2019/10/11/zashho-olga-tokarchuk-otrimala-nobelivsku-premiyu/ (дата обращения: 01.01.2020)

11. Доморосла С. Куда ведет свой плуг польская писательница Ольга Токарчук? Рецензия. 15/03/2017. URL: https://blog.yaka boo.ua/ru/kudy-vede-svii-pluh-polska-pysmennytsia-olha-tokarchuk/ (дата обращения: 01.01.2020)

12. Токарчук О. Веди свой плуг над костями мертвых / пер. с пол. Б. Антоняк. Москва, 2009. 211 с.

13. Токарчук Ольга: «Я навчилась слухати людей». [інтерв'ю від 26-09-2011 з Ольгою Токарчук / провела Л.Шутяк]. Молодий Буковинець: інформ. портал URL: https://ru.molbuk. ua/vnomer/kultura/guest/40893-rus_olga-tokarchuk-ya-navchilasyasluhati-lyudey.html (дата обращения: 01.01.2020).

14. Гари Р. Корни неба / пер. с фр. Е. Голышевой. Москва, 2018. 576 с.

15. Белов И. По нобелевскому счету. Десять лучших книг Ольги Токарчук. Culture.pl. 16.10.2019. URL: https://culture.pl/ru/article /po-nobelevskomu-schetu-desyat-luchshikh-knig-olgi-tokarchuk (дата обращения: 09.01.2020). 